\title{
Meningkatkan Kualitas Produk Pastry Di Anantara Seminyak Bali Resort Melalui Pengolahan Bahan Baku
}

\author{
Luh Putu Sukawati, Ni Made Ary Widiastini, Putu Indah Rahmawati \\ Undiksha
}

\begin{abstract}
Abstrak
Penelitian ini bertujuan untuk mengetahui produk pastry yang di jual di hotel Anantara Seminyak Bali Resort dan strategi yang dilakukan dalam meningkatkan kualitas produk pastry di hotel Anantara Seminyak Bali Resort. Metode pengumpulan data yang digunakan adalah observasi, wawancara dan dokumentasi. Subjek dalam penelitian ini adalah Executive Sous Chef, Chef Pastry, Chef de Partie dan Staff Kitchen Anantara Seminyak Bali Resort. Objek penelitian ini adalah strategi dalam meningkatkan kualitas produk pastry di hotel Anantara Seminyak Bali Resort. Teknik analisis yang dipergunakan adalah deskriptif kualitatif. Hasil penelitian menunjukkan bahwa faktor yang mempengaruhi produk pastry yang dijual di hotel Anantara Seminyak Bali Resort adalah rendahnya penjualan produk pastry dan bahan baku untuk pembuatan kue. Strategi yang dilakukan dalam meningkatkan kualitas produk pastry di hotel Anantara Seminyak Bali Resort adalah membuat inovasi baru yang membuat keunikan di setiap penyajian, hygiene dan sanitasi, serta menjaga dan meningkatkan kualitas makanan.
\end{abstract}

Kata Kunci: Produk pastry, Bahan baku, Kualitas produk Anantara Seminyak Bali

\begin{abstract}
This study aims to find out pastry products sold at Anantara Seminyak Bali Resort hotels and the strategy carried out in improving the quality of pastry products in Anantara Seminyak Bali Resort hotel. Data collection methods used are observation, interviews and documentation. The subjects in this study were the Sous Executive Chef, Pastry Chef, Chef de Partie and Kitchen Staff Anantara Seminyak Bali Resort. The object of this research is a strategy in improving the quality of pastry products at the Anantara Seminyak Bali Resort hotel. The analysis technique used is qualitative descriptive analysis. The results of the study indicate that the factors that influence the pastry products sold at the Anantara Seminyak Bali Resort hotels is low sales of pastry products and raw materials for making cake, the strategy carried out in improving the quality of pastry products at the Anantara Seminyak Bali Resort hotels is making new innovations which makes it unique in every presentation, hygiene and sanitation, and maintaining and improving food quality.
\end{abstract}

Keywords: Pastry products, Raw materials, Product quality Anantara Seminyak Bali

\section{Pendahuluan}

Hotel Anantara Seminyak Bali Resort merupakan Resort berbintang 5 di daerah Seminyak, yang berada di bawah naungan perusahaan Minor International Group. Minor international Group tersebut, didirikan oleh Mr. William Ellwood Heinecke pada tahun 1967 di Thailand, dinamakan Minor karena pada 
tahun 1967 tersebut, Mr. Heinecke baru berusia 17 tahun. Usaha utama dari Minor International Group ada tiga, yakni: Food Group, Hotel Group, dan Trading \& Manufacturing. Hotel Anantara memiliki beberapa contoh nama brand yang dimiliki atau dikelola oleh Minor International Group adalah sebagai berikut: The Pizza Company, The Coffee Club, Esprit, Bossini, Charles \& Keith, dan masih banyak lagi yang lainnya.

Anantara Seminyak Bali Resort merupakan hotel Anantara yang pertama kali beroperasi di Indonesia dan mulai beroperasi pada tanggal 26 April 2008. Saat ini, ada 2 buah Anantara Resort dan 2 buah Anantara Vacation Club yang beroperasi di Indonesia, khususnya di Bali yakni: Anantara Seminyak Bali Resort, Anantara Uluwatu Bali Resort, Anantara Vacation Club Seminyak, dan Anantara Vacation Club Legian.

Anantara adalah sebuah brand yang unik. Ada 3 hal yang membuat Anantara menjadi brand yang unik dan berbeda dengan hotelbrand yang lain yaitu: Anantara story, Anantara brand promise, Anantara brand value. Hotel Anantara seminyak terkenal dengan kehidupan malam (night life) yang dinamakan MoonLite dan terletak di depan pantai dengan pemandangan yang indah.

Hotel Anantara Seminyak Resort memiliki banyak departemen, namun setiap departemen memiliki tugasnya masing-masing, contohnya kitchen salah satu bagian hotel yang tugas utamanya adalah mengolah makanan atau memproduksi makanan. Dapur hotel anantara memegang peranan yang tidak kalah penting dengan bagian-bagian lain yang ada di hotel. Dapur hotel dibagi menjadi beberapa sub bagian yang mempunyai fungsi dan tugas sesuai dengan jenis makanan yang harus disiapkan. Dalam mengolah makanan, seorang karyawan dapur atau juru masak harus mengerti tentang kesehatan dan keberhasilan, pengetahuan memasak, standar resep, standar pelayanan alat dapur dan hal lain tentang makanan. Bagian dari dapur yaitu Hot Kitchen, Cool Kitchen, Gardemanger, Butcher, Main Kitchen dan salah satunya pastry.

Pastry section merupakan bagian yang bertanggung jawab dalam pembuatan cake yang dibutuhkan oleh konsumen dan pihak hotel. Contohnya selalu mempersiapkan cake, bread, tradisonal cake untuk breakfast, lunch, dinner, coffee break, dan dessert. Tepung terigu adalah salah satu bahan utama dalam pembuatan pastry. Tepung terigu diolah dari biji gandum melalui proses penggilingan yang kemudian diolah kembali menjadi berbagai anekaragam 
makanan. Tepung terigu sering digunakan untuk membuat produk pastry lainnya. Dengan menggunakan bahan baku unggulan, pastry section di Hotel Anantara Seminyak Bali Resort akan lebih menghasilkan produk-produk yang berkualitas sehingga dapat meningkatkan pendapatan hotel dalam penjualan produk pastry.

Namun di dalam pembuatan cake yaitu passion basil cake tidak ada sesuatu hal yang baru, sehingga tamu merasa bosan dan tidak mau mencoba, oleh sebab itu apabila di dalam penyajian suatu produk terdapat sesuatu yang berbeda maka tamu tidak akan merasa bosan. Peningkatan product pastry dilakukan dengan cara peningkatan cita rasa, pemberian garnish, keanekaragaman bentuk, dan teknik penyajian. Dari latar belakang di atas, maka perlu diteliti lebih lanjut mengenai judul "Meningkatkan Kualitas Produk Pastry Anantara Seminyak Bali Resort Melalui Pengolahan Bahan Baku“. Berdasarkan penelitian ini penulis meneliti (1).Bagaimana produk pastry yang di jual di Hotel Anantara Seminyak Bali Resort (2).Strategi apa yang perlu dilakukan dalam Meningkatkan Kualitas ProdukPastry di Hotel Anantara Seminyak Bali Resort.

\section{Kajian Pustaka}

\subsection{Bahan Baku Pastry}

Menurut Setiani Tia (2013) Commodity atau bahan baku dalam pengetahuan memasak yaitu semua bahan makanan baik yang berasal dari tumbuhan, hewan maupun olahan dari bahan lain yang dibutuhkan dalam proses produksi makanan serta aman untuk dikonsumsi oleh manusia (food grade). Pada dasarnya bahan baku pastry dibedakan menjadi 2 bagian yaitu :

a. Perisable yaitu bahan makanan yang mudah rusak sehingga membutuhkan tempat dan suhu tertentu dalam penyimpanannya, contoh : susu, keju, dan butter.

b. Groceries yaitu bahan makanan yang tidak cepat rusak dan tidak membutuhkan tempat dan suhu tertentu dalam penyimpanannya. Contoh: tepung, gula dan garam.

\subsection{Kualitas Produk}

Menurut Schiffman dan Kanuk (2007), kualitas produk adalah kemampuan suatu perusahaan untuk memberikan identitas atau ciri pada setiap produknya sehingga konsumen dapat mengenali produk tersebut. Menurut Kotler 
dan Amstrong, (2008), kualitas produk (product quality) merupakan senjata strategi potensial untuk mengalahkan pesaing. Kemampuan dari kualitas produk untuk menunjukkan berbagai fungsi termasuk di dalamnya ketahanan, handal, ketepatan, dan kemudahan dalam penggunan.

Dimensi kualitas produk menurut Tjiptono (2008) yaitu:

1. Performance (kinerja)merupakan karakteristik operasi dan produk inti (core product) yang dibeli, Misalnya kecepatan, kemudahan.

2. Durability (daya tahan), yang berarti daya tahan menunjukan usia produk, yaitu jumlah pemakaian suatu produk sebelum produk itu digantikan atau rusak.

3. Conformanceto specifications (kesesuaian dengan spesifikasi), yaitu kesesuaian yaitu sejauh mana karakteristik desain dan operasi memenuhi standar yang telah ditetapkan sebelumnya.

4. Features (fitur) merupakan karakteristik atau ciri-ciri tambahan yang melengkapi manfaat dasar suatu produk. Fitur bersifat pilihan atau option bagi konsumen. Fitur bisa meningkatkan kualitas produk jika kompetitor tidak memiliki fitur tersebut.

5. Reliability (reabilitas) yaitu kemungkinan kecil akan mengalami kerusakan atau gagal pakai. Misalnya pengawasan kualitas dan desain, standar karakteristik operasional kesesuaian dengan spesifikasi.

6. Aesthetics (estetika) yaitu daya tarik produk terhadap panca indera, misalkan bentuk fisik, model atau desain yang artistik, warna dan sebagainya.

7. Perceived quality (kesan kualitas) yaitu persepsi konsumen terhadap keseluruhan kualitas atau keunggulan suatu produk.

8. Serviceability, yaitu kualitas produk ditentukan atas dasar kemampuan diperbaiki: mudah, cepat, dan kompeten.

\subsection{Strategi Meningkatkan Kualitas Produk Pastry}

Adapun beberapa strategi untuk meningkatkan produk dengan kualitas yang terbaik yaitu dengan memahami keinginan tamu dan melakukan pengolahan produk sebaik mungkin sehingga produk yang dihasilkan berkualitas, dengan cara platting cake semenarik mungkin. Upaya meningkatkan dan menjaga kualitas produk pastry section yaitu dengan mempertahankan proses produksi sesuai standar SOP yang sudah ada dan mengembangkan produk 
yang belum dipahami. Kepuasan tamu ditentukan oleh dua faktor yaitu adanya variasi (garnish) food and beverage serta kualitas pelayanan yang diberikan. Upaya karyawan pastry dalam mengatasi kendala pada saat operasional (kegagalan produk) yaitu dengan cara memahami kendala yang sedang terjadi dan bersikap tenang mengatasi kendala produk bersama-sama sehingga dapat ditemukan solusi dan diatasi.

\section{Metode Penelitian}

\subsection{Rancangan Penelitian}

Penelitian ini dilaksanakan di Anantara Seminyak Bali Resort yang berada di Jl. Abimanyu,Seminyak, Kuta, Kabupaten Badung. Rancangan penelitian yang digunakan adalah deskriptif kualitatif. Penelitian ini dimulai dari observasi awal pada lokasi penelitian yaitu di Anantara Seminyak Bali Resort yang bertujuan untuk mengetahui informasi tentang strategi meningkatkan kualitas produk kitchen di Pastry Anantara Seminyak Bali Resort. Teknik analisis data yang digunakan dalam penelitian ini adalah teknik deskriptif kualitatif. Analisis ini bertujuan untuk memaparkan strategi dalam meningkatkan kualitas produk pastry di Kitchen Pastry Anantara Seminyak Bali Resort. Dari hasil analisis, diharapkan memperoleh penjelasan tentang hal-hal yang diperlukan dan harus dilakukan dalam meningkatkan pengolahan bahan baku produk pastry yang berkualitas di

Kitchen Pastry Anantara Seminyak Bali Resort.

\subsection{Hasil Penelitian dan Pembahasan}

\subsubsection{Food Production Department Anantara Seminyak Bali Resort}

Department Food and Beverage Product merupakan salah satu departemen yang terdapat di Anantara Seminyak Bali Resort yang memiliki tugas dan tanggung jawab memberikan pelayanan terhadap tamu dalam hal layanan makanan dan minuman. Sebagai salah satu hotel berbintang lima yang ada di Bali, Anantara Seminyak Bali Resort memiliki 2 (dua) outlet restoran dengan satu tempat produksi yang sama untuk memfasilitasi kebutuhan tamu terhadap makanan dan minuman. 2 (dua) outlet restoran yang dimiliki Anantara Seminyak Bali Resort yaitu :

1. The Wild Orchid Restaurant 
The Wild Orchid Restaurant merupakan salah satu restaurant yang ada di Anantara Seminyak Bali. Restaurant ini merupakan all day dining, karena di restaurant ini tamu bisa menikmati breakfast, lunch dan dinner. Selain menikmati makanan dan minuman yang disajikan oleh para waiter/ss, tamu juga bisa menikmati indahnya pemandangan pantai dan sunset di saat sore hari.

\section{SOS ( Sunset On Seminyak )}

SOS ( Sunset On Seminyak ) merupakan Bar and Restaurant yang bukadari jam 5 sore sampai jam 7 malam. Di SOS ini sangat cocok untuk para tamu yang ingin melihat keindahan sunset sambil menikmati minuman baik alcohol maupun non-alkohol yang diinginkan. Di samping itu selagi menikmati minuman dan melihat indahnya sunset di sore hari, tamu juga

akan diiringi dengan music dari para DJ internasional.

Adapun beberapa bagian di kitchen di hotel anantara yaitu :

1. Main Kitchen adalah salah satu outlet kitchen yang dimiliki Anantara Seminyak Bali Resort dimana kitchen ini dibuka 24 jam untuk memenuhi kebutuhan tamu yang menginap. Kitchen ini bertugas menyiapkan berbagai jenis makanan untuk breakfast, lunch, dinner dan room service.

2. Gardemanger adalah salah satu outlet kitchen di Anantara Seminyak Bali Resort dibuka 24 jam yang menyediakan makanan appetizer dan aneka buah-buahan.

3. Pastry adalah outlet kitchen yang bertugas membuat dessert dan berbagai jenis kue ini dibuka pukul $06.00 \mathrm{am}-11.00 \mathrm{pm}$.

4. Butcher merupakan outlet kitchen yang bertanggung jawab dalam proses pemotongan segala jenis daging, baik itu seafood maupun meat.

\subsubsection{Job Description}

Tugas dan tanggung jawab masing-masing jabatan, yaitu :

\section{Executive Sous Chef}

a). Membuat menu-menu yang akan dijual.

b). Mengontrol kegiatan para staff kitchen.

\section{Sous Chef}

a). Asisten Chef yang membantu segala tugas Chef.

b). Mencari perbandingan harga dan bahan. 


\section{Chef De Partie}

a). Menjadi menjadi Chefoutlet.

b). Menjadi seorang leader di outletnya.

\section{Demi Chef}

a). Leader di outletnya.

b). Menjadi asisten Chef de Partie.

\section{Cook/Commis}

a). Mengolah atau memasak makanan yang diproduksi pada masing-masing bagian.

b). Mengolah berbagai pendamping makanan utama seperti memasak sayuran, mengolah nasi dan pasta.

\section{Cook Helper}

a). Membantu pekerjaan Cook, seperti mengupas kentang, memotong sayuran, dan memasak makanan sederhana.

\section{Chief Steward}

a). Mempersiapkan alat-alat yang akan digunakan di kitchen.

b). Membersihkan areal kitchen.

8. Steward Supervisior

a). Menjadi leader para anak buahnya.

b). Membersihkan semua peralatan yang ada di kitchen.

\section{Steward Attendant}

a). Membersihkan semua peralatan yang ada di kitchen.

b). Bertanggung jawab atas apa yang dilakukannya saat bekerja.

\subsubsection{Produk Pastry yang di jual di Hotel Anantara Seminyak Bali Resort.}

Di Hotel Anantara Seminyak memiliki beberapa produk yang mewakili dari sekian banyak produk pastry yang dijual dan sudah mengikuti standar operasional prosedur (SOP) yang sudah ada sehingga dalam proses pembuatan pastry juga harus memperhatikan beberapa hal, tidak hanya penggunaan standar recipe tetapi bahan baku yang digunakan juga sangat berpengaruh karena salahnya menggunakan bahan baku akan mengakibatkan kurangnya cita rasa pada produk pastry. Adapun permasalahan saat pembuatan produk pastry dan cara menanganinya yaitu :

1. Permasalahan yang dihadapi saat pembuatan produk pastry 
Pertama saat pembuatan passion basil cake, dalam pemilihan bahan baku yang digunakan tidak konsisten maka setiap menghasilkan produk pastry mengalami perbedaan yang bisa dilihat dari teksurnya, cita rasa dan lain sebagainya. Adapun permasalahan saat pembuatan produk pastry dan cara menanganinya yaitu :

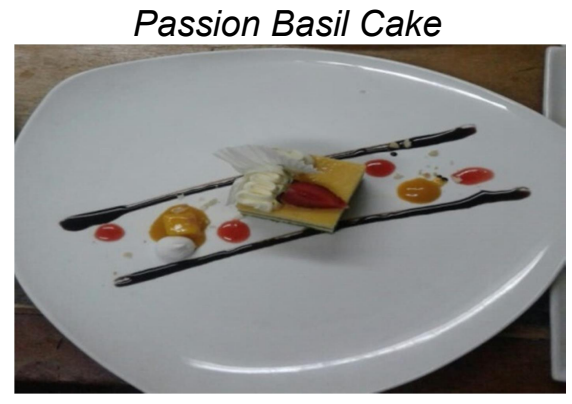

2. Cara menangani produk pastry

Adapun cara untuk menangani hasil produk pastry yang kurang diminati oleh tamu dan kurangnya daya jual di hotel Anantara Seminyak antara lain dengan cara menggantikan dengan hasil produksi yang baru yaitu Mango Sagoo

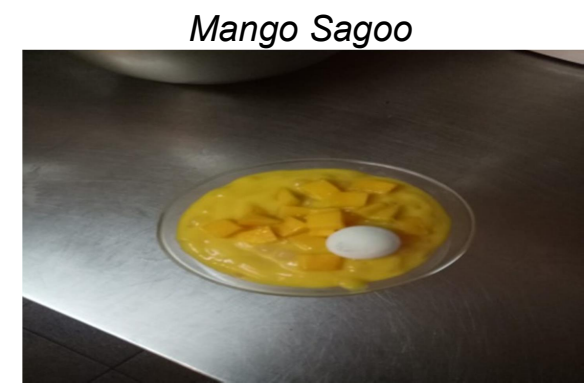

Beberapa produk yang mewakili dari sekian banyak produk pastry yang dijual di hotel Anantara Seminyak yaitu :

BackForest Cake

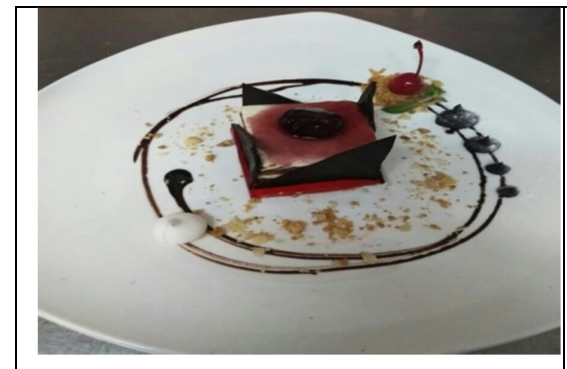

Ginger Plan

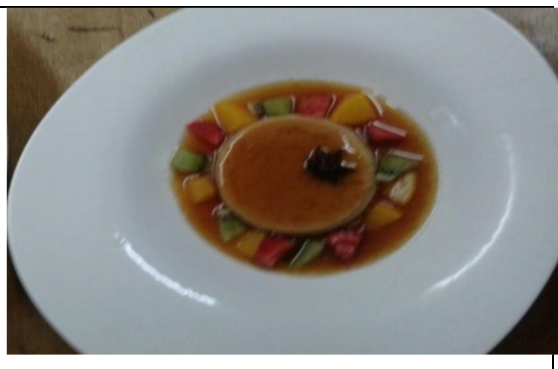




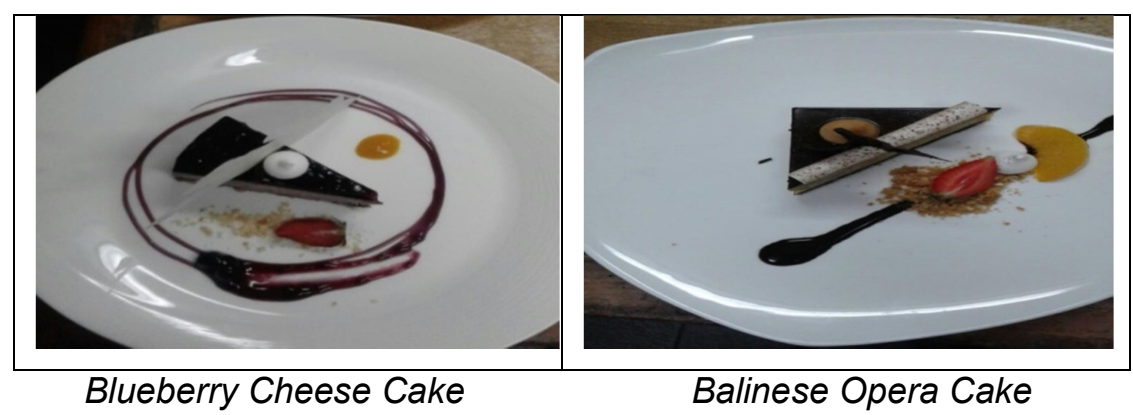

\subsubsection{Strategi yang dilakukan dalam Meningkatkan Kualitas Produk \\ Pastry di Hotel Anantara Seminyak Bali Resort.}

Dalam Persaingan kemampuan perusahaan dalam memenuhi kebutuhan pelanggan sangat mempengaruhi tingkat mutu yang diberikan oleh perusahaan meliputi kualitas produk serta ketepatan waktu. Semakin tinggi tingkat mutu perusahaan terhadap kebutuhan pelanggan, maka akan semakin tinggi tingkat terpenuhinya kebutuhan pelanggan yang bisa dinyatakan dengan tingkat kepuasan tamu. Berdasarkan hal itu,maka perusahaan diharuskan untuk dapat meningkatkan secara terus-menerus kemampuan produksinya dalam menghasilkan produk yang berkualitas sesuai dengan keinginan pelangganya di hotel Anantara Seminyak

Bali Resort :

1. Untuk menjaga kualitas produk pastry tentunya tidak lupa agar tetap menjaga Hygiene dalam meningkatkan kualitas produk tetapi harus menampilkan presentasi makanan yang unik, menarik dan cantik saat di pandang, agar terciptanya makanan yang berkualitas maka staff kitchen agar tetap menjaga standar operasional prosedur (SOP) yang sudah ada disetiap perusahaan itu sendiri.untuk menjaga kualitas makanan yang akan disajikan maka standard rasa dari produk tersebut harus stabil, menampilkan presentasi yang cantik, selalu menjaga kerbersihan diri dan kerapian saat penyajian sehingga akan memberikan rasa yang aman bagi

customer.

2. Mengadakan training atau pelatihan yang berhubungan mengenai produk pastry akan meningkatkan kualitas produk pastry di hotel anantara seminyak bali resort. Training yang diselenggarakan berupa beverage training, food training, hygiene dan sanitasi di hotel. sasaran 
pelatih kerja yaitu seluruh staff kitchen di hotel. Melalui program training yang rutin dilakukan di hotel anantara seminyak akan mampu meningkatkan kualitas makanan di hotel dan akan menciptakan kreativitas di setiap staff kitchen.

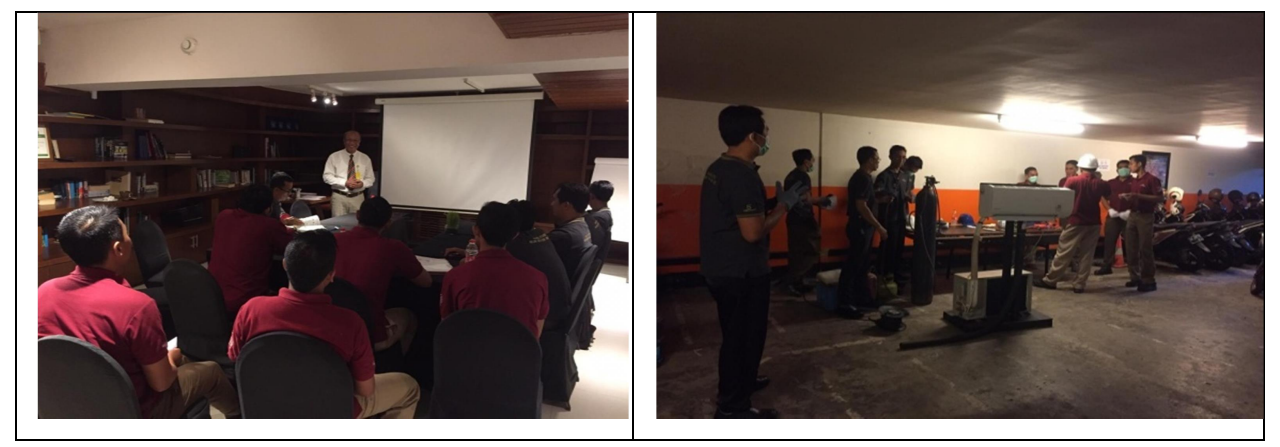

\section{Penutup}

Penulis dapat menarik beberapa kesimpulan yang berhubungan dengan judul yang penulis angkat. Kesimpulan tersebut antara lain:

1. Dalam pembuatan produk pastry pasti akan menemui hambatanhambatan didalamnya. Adapun hambatan yang ditemui di hotel Anantara Seminyak Bali Resort yaitu dengan pembuatan passion basil cake lainnya, dengan memahami keinginan tamu dan melakukan pengolahan produk sebaik mungkin sehingga produk yang dihasilkan berkualitas, strategi meningkatkan kualitas produksi pastry yaitu dengan mempertahankan proses produksi sesuai standar SOP yang sudah ada.

2. Adapun upaya-upaya yang dilakukan untuk meningkatkan kualitas produk pastry di hotel Anantara Seminyak Bali Resort yaitu mendalami produk pastry dengan mengikuti training atau seminar yang berhubungan dengan pastry dan menciptakan produk pastry yang unik dan menarik agar tamu puas dengan hasil kinerja kerja pastry.

\section{Daftar Pustaka}

Arikonto. (2016). Prosedur penelitian suatu pendekatan praktik. Jakarta: Rineka Cipta.

Kotler, Philip \& Gary Armstrong. 2008. Prinsip-Prinsip Pemasaran. Jakarta: Erlangga.

Schiffman dan Kanuk. 2007. Perilaku konsumen. Edisi 7. Jakarta: Indeks. 
Sihite, Richard. 2000. Food Product (Dasar-Dasar Tata Boga). Surabaya: Penerbit SIC.

Subagjo, Adjab. 2007. Manajemen Pengolahan Kue dan Roti, Yogyakarata: Graha IImu.

Syarbini, STP,M.Husin. 2013. A-Z Bakery, Solo: Tiga Serangkai.

Tia, Setiani. 2013. Apa itu pastry http:/pastrykuaja.blogspot.co.id/2013/10/apaitu-pastry.html. Diakses tanggal 9 April 2019.

Tjiptono, Fandy. 2008. Strategi Pemasaran. Yogyakarta: Andi.

P.H.,S.E, Bartono \& E.M.,S.E, Ruffino. 2010. Tata Boga Industri, Yogyakarta: Andi. 